\section{PRINT ISSN 1119-8362 ELECTRONIC ISSN 1119-8362}

Full-text Available Online at https://www.ajol.info/index.php/jasem http://ww.bioline.org.br/ja

\title{
Modelling and Simulation of High Density Polyethylene Liner Installation in Engineered Landfill for Optimum Performance
}

\author{
${ }^{1 *} \mathrm{IKPE}, \mathrm{AE} ;{ }^{2} \mathrm{NDON}, \mathrm{AE} ;{ }^{3} \mathrm{ADOH}, \mathrm{AU}$ \\ ${ }^{I}$ Department of Mechanical Engineering, ${ }^{3}$ Department of Production Engineering University of Benin, P.M.B. 1154, Nigeria, \\ ${ }^{2}$ Department of Civil Engineering, Akwa Ibom State University, Mkpat Enin, Akwa Ibom State, Nigeria \\ *Corresponding Author Email: aniekan.ikpe@eng.uniben.edu, other Emails:ibiamndon@outlook.com; adoh.azum@gmail.com
}

\begin{abstract}
Geomembrane liner is an important part of a landfill system that must be selected and installed properly to avoid high induced stresses and imperfections. Considering a fixed HDPE liner thickness of $2 \mathrm{~mm}$ and variable masses in this study, the liner was modelled and simulated for 27 scenarios using Solidworks and Artificial Neural Networking approach. Static analysis was further performed on the Solidworks model under a distributed load of 4000kg in properly aligned and improperly aligned conditions to the base and side walls of a landfill system. The minimum stress and width of imperfection obtained from the Solidworks simulation was $77 \mathrm{MPa}$ and $34 \mathrm{~mm}$ while $65 \mathrm{MPa}$ and $67 \mathrm{~mm}$ was obtained from the ANN simulation. The liner failed outrageously in the improperly aligned condition with maximum induced stress of 3,606.521 MPa, but no sign of failure was observed for the properly aligned condition which the maximum stress $(0.018 \mathrm{Mpa})$ was quite low. This investigation can serve as a guide towards proper installation of geomembrane liners for optimum performance in landfill applications.
\end{abstract}

\section{DOI: https://dx.doi.org/10.4314/jasem.v23i3.13}

Copyright: Copyright (C) 2019 Ikpe et al. This is an open access article distributed under the Creative Commons Attribution License (CCL), which permits unrestricted use, distribution, and reproduction in any medium, provided the original work is properly cited.

Dates: Received: 20 February 2019; Revised: 19 March 2019; Accepted 26 March 2019

Keywords: Solid waste, engineered landfill, Geomembrane liner, Installation

An engineered landfill system also known as sanitary landfill is a waste containment facility that involves carefully engineered excavation of the ground and burying/compaction of waste materials in layers to protect the environment against the effects of landfill gas and leachate from decomposing organic waste (Ikpe et al., 2018; Orhorhoro et al., 2018). Leachate which contains organic and inorganic chemicals, acidic oxides such as $\mathrm{SO}_{2}$ and NOx, heavy metals as well as pathogens is a toxic liquid product from decomposing organic waste (Ikpe et al., 2019a; Rowe and $\mathrm{Yu}, 2013)$. As a result of the toxic nature of leachate, Ikpe et al. (2019b) recommended that HDPE liner be integrated into landfill systems and other waste containment facilities to minimise the rate at which toxic contaminants percolate into the soil and groundwater. HDPE as defined by ASTM D 883 is the industry standard for a wide range of waste management applications such as primary and secondary containment for MSW or hazardous waste landfill systems, caps/closures for landfill, waste water treatment lagoon, mining applications etc. (Shakeri et al., 2012). Studies have proven that HDPE offers desirable strength in landfill applications (Jafari et al., 2014), especially for bottom liners, due its relatively high resistance to aggressive leachate components (Rowe, 2001). In addition, it consists of $96-97.5 \%$ of polyethylene resin, 2-3\% of carbon black and $0.5-$ $1.0 \%$ of other additives such as antioxidants and stabilizers. The resin used is mainly a linear copolymer polymerized using ethylene and $\alpha$-olefin as comonomer under low pressure with adequate catalysts (Rowe et al., 2013). Polyethylene as lining membrane has the structure of crystal lamellae where the polyethylene chains are neatly folded and tightly packed with amorphous layers where the chains or chain segments are disordered (Apse, 1989). The lamellae are linked by tie molecules that start and end in the adjacent lamellae, and some of the inherent properties of polyethylene depend on the packing structure as well as the changes in the molecular packing which may alter the durability and the overall performance of the lining membrane (Rowe and Sangam, 2002). The application of synthetic liner in a landfill system can be affected by certain factors such as installation damage, bad design and/or choice of materials, aging, pipes penetrating the liner, geotechnical failure, unanticipated chemical attack, tension of the materials, puncture, uncontrolled groundwater infiltration, instability of the sub-grade both slope and basal heave (Thusyanthan et al., 2007; Xue et al., 2013). According to Alberto (2011), lining materials in engineered landfill systems can fail to meet their expected design life due to delay in

*Corresponding Author Email: aniekan.ikpe@eng.uniben.edu 
settlement, improper compaction, bad design and/or choice of materials, geo-technical failure, uncontrolled groundwater infiltration, instability of the sub-grade both slope and basal heave, increase in hydraulic conductivity due to interaction with leachate. Improper contact between the bottom liner (such as folded area in the liner) and the compacted bottom soil can result in imperfections that may accelerate the rate of leakage through deteriorated areas of the bottom liner. Under such conditions, the leachate can spread across the compacted soil layer and consequently seep into the ground to contaminate ground water (Kocasoy and Curi, 1995; Loo et al., 2018; Blight, 2008). In this study, HDPE liner was modelled and simulated to determine optimum operation parameters and installation techniques for engineered landfill application.

\section{MATERIALS AND METHODS}

Design variables specified by Environmental Protection Agency for the design, operation and rehabilitation of landfills were employed as inputs for the Geomembrane Liner models developed with Artificial Neural Network (ANN) and Solidworks. The models were simulated for twenty seven (27) scenarios at a fixed thickness of $2 \mathrm{~mm}$ and varying masses to check for corresponding minimum imperfections and minimum stresses. The Solidworks model was statically analysed in two (2) in conditions where the lining membrane is properly aligned with the base and sidewalls of a landfill system and where the base of the lining membrane was not in contact with the base of the landfill system (in tension). A load of $4000 \mathrm{k}$ was considered as the gross weight of solid waste and granular materials acting on the lining membrane. It was assumed that the load which is evenly distributed across the geomembrane containment represents the lateral and tensile forces acting on the geomembrane liner. Forces acting on the geomembrane liner is transmitted by gravity and can take place in various forms depending on the compaction rate, weight of landfilled waste, moisture content etc. However, normal force $(\mathrm{N})$ acting on the liner is given by equation 1 (Qian et al., 2001; Koerner, 2012);

$\mathrm{N}=\mathrm{W} \cos \beta$

Where, $\mathrm{W}$ is the weight of the liner per unit width and $\cos \beta$ is the angle of the landfill side slope.

To determine the maximum friction force $\left(\mathrm{F}_{\max }\right)$ on the liner, equation 2 can be considered;

$\mathrm{F}_{\text {max }}=\mathrm{Nf}$

Where, $\mathrm{f}$ is the friction factor for the liner given by equation 3;
$\mathrm{f}=\mathrm{N} \tan \phi=\mathrm{W} \cos \beta \tan \phi$

Where, $\tan \phi$ is the friction angle.

In addition, tensile force $\left(\mathrm{F}_{\mathrm{T}}\right)$ acting on the liner is given by equation 4 ;

$\mathrm{F}_{\mathrm{T}}=\mathrm{W} \operatorname{Sin} \beta-\mathrm{F}=\mathrm{W} \operatorname{Sin} \beta-\mathrm{W} \cos \beta \tan \phi(4)$

For net force acting on liner at the top of the slope, the relationship is given by equation 5 ;

$\mathrm{F}_{\mathrm{L}}=\mathrm{W} \operatorname{Sin} \beta-\mathrm{F}=\mathrm{W} \operatorname{Sin} \beta-\mathrm{W} \cos \beta \tan \phi(5)$

However, the total stress on the liner can be determine by considering the total mass acting on it. This is given by equation 6 (Das and Khaled, 2017);

$\sigma_{\mathrm{T}}=-\int_{\text {bottom }}^{\text {top }}\left(\mathrm{n} \rho_{\mathrm{l}}+\rho_{\mathrm{b}}\right) \mathrm{gdz}$

In the presence of gas mixture, the total stress may be modified as given by equation 7 :

$\sigma_{\mathrm{T}}=-\int_{\text {bottom }}^{\text {top }}\left(\mathrm{nS}_{\mathrm{l}} \rho_{\mathrm{l}}+\mathrm{nS}_{\mathrm{g}} \rho_{\mathrm{g}}+(1-\mathrm{n}) \rho_{\mathrm{s}}\right) \mathrm{gdz}$

The weight of the liner $(\mathrm{W})$ per unit width is given by equation 8 ;

$\mathrm{W}=\mathrm{g} \rho_{\mathrm{L}} \mathrm{t}$

Where, $\mathrm{t}$ is the liner thickness and $\rho_{\mathrm{L}}$ is the liner density $=0.92-1.4 \mathrm{~g} / \mathrm{cm}^{3}$;

Tension in membrane liner is due to the overlying weight $(\mathrm{W})$ of organic waste, mobilized upper and lower interface friction angle $\left(\delta_{\mathrm{u}}, \delta_{\mathrm{i}}\right)$ between the liner and soil layers as well as the slope angle $(\beta)$ expressed in equation 9 Thusyanthan et al. (2007);

$T=f\left(W, \delta_{u}, \delta_{l}, \beta\right)$

Tension in the geomembrane liner is calculated by equation 10 ;

$T=\sigma_{\text {all }} \times t$

Where, $\mathrm{T}$ is the tension mobilized in the liner, $t$ is the liner thickness and $\beta$ is the slope angle of the liner across the landfill system.

The vertical force component which is assumed to be distributed along the mobilization distance is part of the normal stresses imposed by the overlying solid waste and the granular layer. The relationship is given by equation 11 and 12 , and $\mathrm{T}$ can further be solved in by equation 13 ; 
$T \cos \beta=F_{\sigma u}+F_{\sigma l}+F_{\sigma T}$

$T \cos \beta=\sigma_{n} \tan \delta_{l}(x)+0.5(2 T \sin \beta /$

$x) \mathrm{x} x \tan \delta_{l}+\sigma_{n} \tan \delta_{u}(x)$

Where, $F_{\sigma u}$ and $F_{\sigma l}$ are friction forces between upper layer and lower layer of the liner and soil layer, and $F_{\sigma T}$ is the normal stress imposed by friction angle of the overlying solid waste.

$T=\frac{\sigma_{n} x\left(\tan \delta_{u}+\tan \delta_{l}\right)}{\cos \beta-\sin \beta \tan \delta_{l}}$

From the derivations in equation 10 and 13, the general equation for calculating the thickness of a geomembrane liner is given by equation 14 (Koerner, 2012);

$t=\frac{\sigma_{n} x\left(\tan \delta_{u}+\tan \delta_{l}\right)}{\sigma_{\text {all }}\left(\cos \beta-\sin \beta \tan \delta_{l}\right)}$
Modelling with Solidworks: As mentioned earlier, the material used in lining the walls of the landfill system is made of HPDE (High Density polyethylene) material. The liner was modelled with SolidWorks using surface Primitives, and the HPDE material was applied to the model. After the appropriate fixtures were applied, mass of the waste and mass of the granite were the two load case scenarios considered. The total distributed mass of waste was measured as $1763 \mathrm{~kg}$, while the measured mass of granular layer was approximately $2000 \mathrm{~kg}$, and the sum total of these masses were used as the applied load (acting on the liner) in the stress analysis. The liner was analysed for two conditions as follows; (i) The lining material was not in proper contact with the side walls and base of the landfill system. (ii) The lining material was aligned (full contact) to fit the side walls and base of the landfill system. A load of approximately $4000 \mathrm{Kg}$ (being the mass of organic waste and granite deposited in the system) was applied on the HDPE liner model for both conditions. The design input variables specified for geomembrane liner are presented in Table 1.

Table 1. Design Input Variables Specified for Geomembrane Liner

\begin{tabular}{lllll}
\hline Input Variable & Max Values & Min Values & Optimum Requirement & Units \\
\hline Thickness (EPA, 2014) & 2.5 & 1.5 & 2 & $\mathrm{~mm}$ \\
Mass (Material unit weight) & - & - & - & $\mathrm{g}$ \\
Applied Load & 4000 & & & $\mathrm{~kg}$ \\
Output Parameters & Requirement & Analysis & - & Unit \\
Stress & Minimum & Static & - & $\mathrm{N} / \mathrm{mm}^{\wedge} 2(\mathrm{MPa})$ \\
Width of imperfection & minimum & Static & - & $\mathrm{mm}$ \\
\hline
\end{tabular}

Modelling with ANN: The network training diagram generated for the prediction of induced stress on the geomembrane using back propagation neural network is presented in Fig 1.

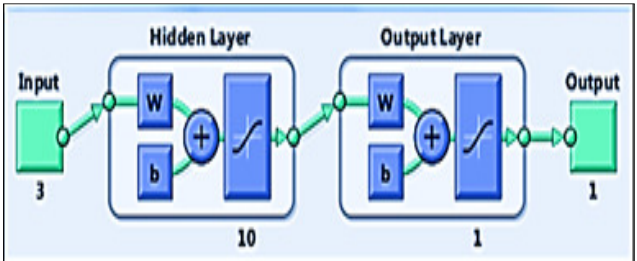

Fig. 1. Network Training Diagram for Predicting Induced Stress on the Liner

Performance evaluation plot which shows the progress of training, validation and testing is presented in Fig 2. From the performance plot of Fig 2, no evidence of over fitting was observed. Moreover, similar trend was observed in the behavior of the training, validation and testing curve which is expected since the input variables were normalized before use. Lower mean square error is a fundamental criteria used to determine the training accuracy of a network. An error value of $3.0434 \mathrm{e}-09$ at epoch 10 is an evidence of a network with strong capacity to predict the induced stresses. The training state, which shows the gradient function, the training gain $(\mathrm{Mu})$ and the validation check, is presented in Fig 3.

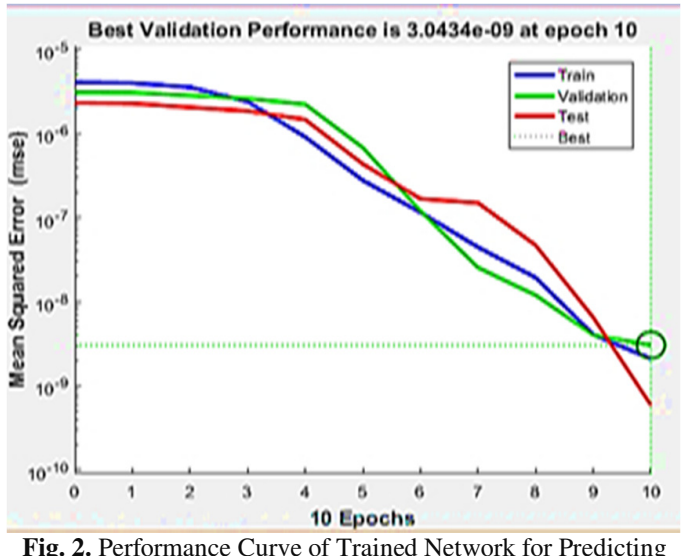

Fig. 2. Performance Curve of Trained Network for Predicting induced Stress on the Liner

Back propagation is an approach used in artificial neural networks to calculate the error contribution of each neuron after a series of data training. In this case, 
the neural network calculated the gradient of the loss function to explain the error contributions for each of the selected neurons (Owunna and Ikpe, 2019).



Fig. 3. Neural Network Training State for Predicting induced Stress on the Liner

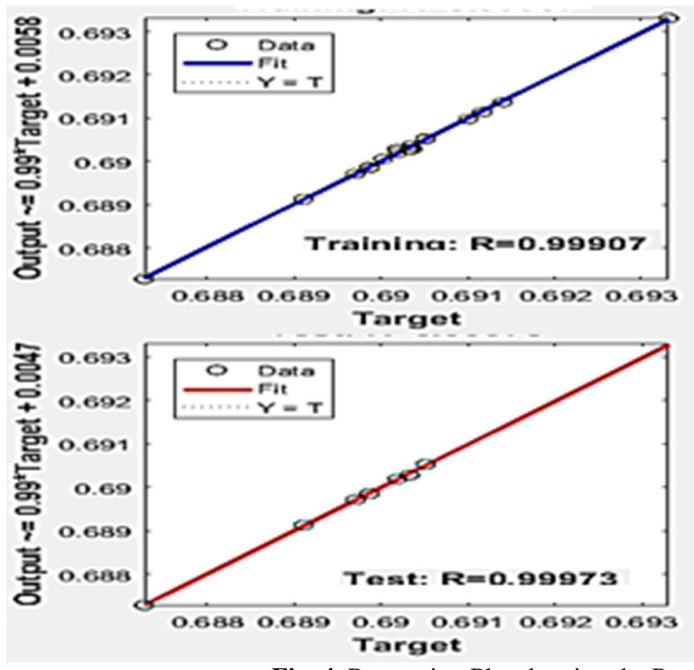

Fig. 4. Regression Plot showing the Progress of Training, Validation and Testing
Hence, obtaining lower error in the network training process is better and indicates accuracy of the output obtained. Computed gradient value of $7.8095 \mathrm{e}-08$ was obtained as shown in Fig 3, indicating that the error contributions of each selected neurons is very minimal. Momentum gain $(\mathrm{Mu})$ is the control parameter for the algorithm used to train the neural network. It is the training gains and its value must be less than unity. Momentum gain of $1.0 \mathrm{e}-13$ shows a network with high capacity to predict the induced stress. The regression plot which shows the correlation between the input variables and the output variable (Induced stress), progress of training as well as the validation and testing are presented in Fig 4.

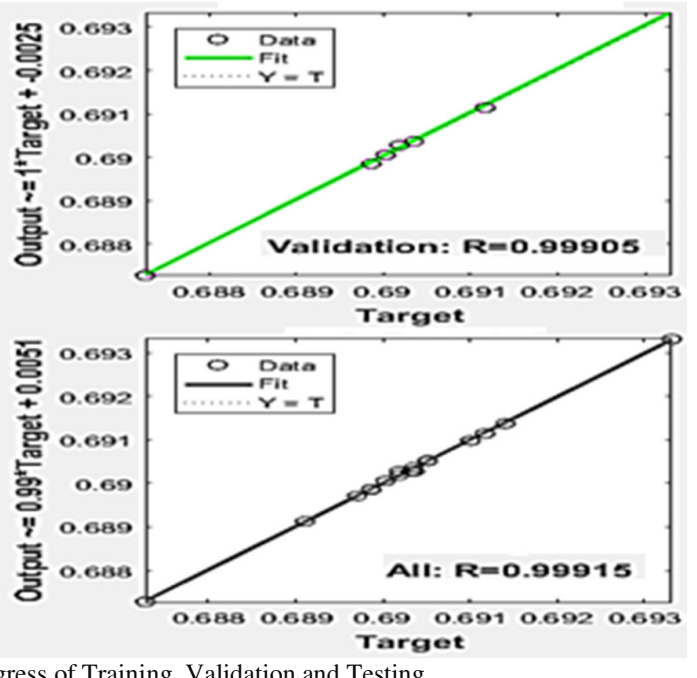

Based on the computed values of the correlation coefficient (R) as observed in Fig 4, it was presumed that the network has been trained accurately and can be employed in the prediction of induced stress on the geomembrane liner. To test the reliability of the trained network, the neural network was further employed in the prediction of its own values for induced stress using the same set of input parameters (fixed thickness of $2 \mathrm{~mm}$ and variable masses) generated from the central composite design. The same procedures were also performed to obtain predicted values for width of imperfections on the geomembrane liner.

\section{RESULTS AND DISCUSSION}

Typical thickness for landfill geomembrane basal liner systems ranges from 1.5 to $2.5 \mathrm{~mm}$. Minimum thickness of $2.00 \mathrm{~mm}$ is recommended for geomembrane liner as it provides optimum resistance to contaminant breakthrough, thereby, increasing the containment system design life. The sizable thickness improves the tear, tensile strength and puncture resistance (EPA, 2000). Thickness of $2 \mathrm{~mm}$ was maintained in all scenarios. Mass of the HDPE liner was varied in all scenarios. Mass of organic substrate and the mass of granular layer which is assumed to be the load (force) acting on the liner was $4000 \mathrm{~kg}$. Output responses were the induced stress distribution across the liner and the corresponding width of impaction. Using design variables shown in Table 1, design studies (presented in Table 2) was carried out for 27 scenarios using Solidworks and ANN to determine the optimal geomembrane thickness for stress, and minimum mass for optimum service performance of the material. 
Table 2. Solidworks and ANN Design Study for Optimal performance of HDPE

\begin{tabular}{|c|c|c|c|c|c|c|c|c|}
\hline \multirow[b]{2}{*}{ Scenarios } & \multicolumn{4}{|c|}{ Solidworks Design Study } & \multicolumn{4}{|c|}{ ANN Design Study } \\
\hline & $\begin{array}{l}\text { Thickness } \\
(\mathrm{mm})\end{array}$ & $\begin{array}{l}\text { Width of } \\
\text { imperfection }(\mathrm{mm})\end{array}$ & $\begin{array}{l}\text { Stress } \\
(\mathrm{MPa})\end{array}$ & Mass (g) & $\begin{array}{l}\text { Thickness } \\
(\mathrm{mm})\end{array}$ & $\begin{array}{l}\text { Width of } \\
\text { imperfection }(\mathrm{mm})\end{array}$ & $\begin{array}{l}\text { Stress } \\
(\mathrm{MPa})\end{array}$ & $\begin{array}{l}\text { Mass } \\
(\mathrm{g})\end{array}$ \\
\hline 1 & 2 & 22.5 & 0.0653 & 6050.2 & 2 & 22.2 & 0.0723 & 6050.2 \\
\hline 3 & 2 & 22.5 & 0.0616 & 9333.6 & 2 & 22.4 & 0.0715 & 9333.6 \\
\hline 4 & 2 & 21.5 & 0.0687 & 3110.6 & 2 & 22.3 & 0.0732 & 3110.6 \\
\hline 5 & 2 & 22.5 & 0.0539 & 6221.2 & 2 & 23.5 & 0.0623 & 9331.9 \\
\hline 8 & 2 & 22.5 & 0.0601 & 6221.0 & 2 & 23.1 & 0.0706 & 6221.0 \\
\hline 9 & 2 & 22.5 & 0.0507 & 9331.6 & 2 & 23.3 & 0.0603 & 9331.6 \\
\hline 10 & 2 & 45.8 & 0.0593 & 3163.1 & 2 & 46.2 & 0.0689 & 3163.1 \\
\hline 11 & 2 & 45.0 & 0.0409 & 6326.5 & 2 & 45.4 & 0.0504 & 6326.5 \\
\hline 12 & 2 & 45.4 & 0.0392 & 9489.9 & 2 & 46.3 & 0.0491 & 9489.9 \\
\hline 17 & 2 & 45.0 & 0.0289 & 6314.1 & 2 & 45.6 & 0.0376 & 6314.1 \\
\hline 18 & 2 & 45.0 & 0.0301 & 9471.2 & 2 & 46.2 & 0.0205 & 9471.2 \\
\hline 19 & 2 & 67.5 & 0.0427 & 3236.5 & 2 & 66.8 & 0.0521 & 3236.5 \\
\hline 20 & 2 & 67.5 & 0.0445 & 6473.8 & 2 & 67.2 & 0.0552 & 6473.8 \\
\hline 21 & 2 & 65.5 & 0.0411 & 9712.2 & 2 & 66.5 & 0.0540 & 9712.2 \\
\hline 22 & 2 & 63.5 & 0.0276 & 3207.5 & 2 & 64.3 & 0.0372 & 3207.5 \\
\hline 23 & 2 & 65.5 & 0.0277 & 6415.1 & 2 & 63.6 & 0.0347 & 6415.1 \\
\hline 24 & 2 & 66.5 & 0.0277 & 9622.8 & 2 & 67.2 & 0.0346 & 9622.8 \\
\hline 25 & 2 & 63.5 & 0.0274 & 3204.5 & 2 & 62.8 & 0.0382 & 3204.5 \\
\hline 26 & 2 & 67.5 & 0.0277 & 6409.1 & 2 & 66.7 & 0.0351 & 6409.1 \\
\hline 27 & 2 & 64.5 & 0.0274 & 9613.7 & 2 & 65.1 & 0.0364 & 9613.7 \\
\hline
\end{tabular}

From the design studies presented in Table 2, optimal solution for design study from Solidworks simulation occurred at scenario 7 with mass of 3110.54 grams $(3.11 \mathrm{Kg})$, thickness of $2 \mathrm{~mm}$, lowest stress of 0.01852 $\mathrm{MPa}$ and $15.5 \mathrm{~mm}$ minimum width of imperfection. From the design study in Table 2, optimal solution for design study from ANN simulation occurred at scenario 6 with mass of 3110.54 grams $(3.11 \mathrm{Kg})$, thickness of $2 \mathrm{~mm}$, lowest stress of $0.01924 \mathrm{MPa}$ and $16.2 \mathrm{~mm}$ minimum width of imperfection. From the predicted minimum induced stress and minimum imperfection values obtained for the geomembrane liner from Solid works and ANN simulation in Fig 2 and 3 , there is proximity in the values which indicates correctness in the values predicted and accuracy of the two software. In addition to the results obtained in Table 2, the landfill basal liner was statically analyzed in two conditions under a distributed load of $4000 \mathrm{~kg}$. The conditions were; when the liner is properly aligned (proper contact) with the base and side walls of the landfill system and when proper alignment of the liner with the base and sidewalls of the landfill system is not established. Figure 5-7 represent Solidworks simulated results for static analysis of the geomembrane lining material that was not in proper contact with the side walls and base of the landfill system. From the static analysis, maximum von-mises stress on the HDPE liner was $3606 \mathrm{MPa}$ with maximum displacement of $4.35822 \mathrm{~mm}$ and maximum equivalent strain of 1.76512 . Considering the Von- mises failure theory, material component is said to be in a state of failure if the maximum Von-mises stress resulting from the applied load exceeds the material yield strength, but if the Von-mises stress value is less than the material's yield strength, it can be concluded that the material still has the capacity to withstand additional load before failure. This relates to the theory behind elasticity of materials which states that a given material can withstand additional load acting on it provided its elastic limit is not exceeded (Ikpe and Owunna, 2017). In this case, referenced yield strength of the HDPE liner from Solidworks material library is $29.5 \mathrm{~N} / \mathrm{mm}^{\wedge} 2$ and the maximum Von-mises stress obtained for HDPE liner in the static analysis when it is not properly aligned with the base and side walls of the landfill system is $3,606.521 \mathrm{~N} / \mathrm{mm}^{\wedge} 2$. This implies that the liner under such condition has already failed and would give way for landfill leachate which it is designed to accommodate to percolate into the landfill underlying soil and ground water. This high value of Von-mises stress for the improperly aligned condition of the HDPE can also triggered an increase in the resultant displacement and equivalent strain. This is because, the high Von-mises stress distribution on the liner is characterized by strain as it stretches under the influence of external load while the strain displaces the atomic bonding within the molecular structure of the liner. Thus, the material continues to stretch under the influence of external load until a point is reach where its elastic limit is exceeded and it snaps because it has 
no further capacity to hold onto the load acting on it. This is in agreement with the findings of Ikpe et al. (2017).

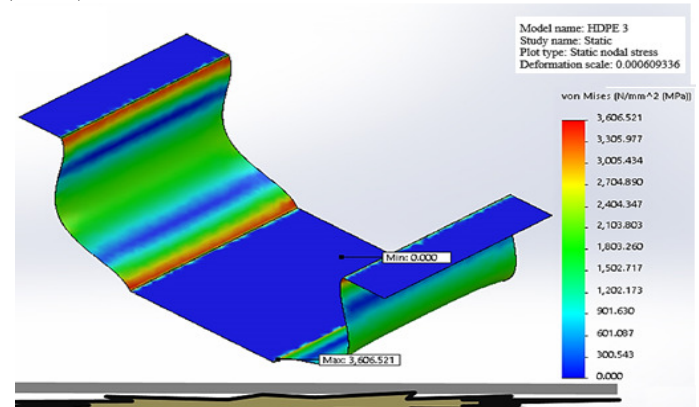

Fig. 5. Stress Distribution on HDPE Liner with improper Contact with the Landfill Internal Surfaces

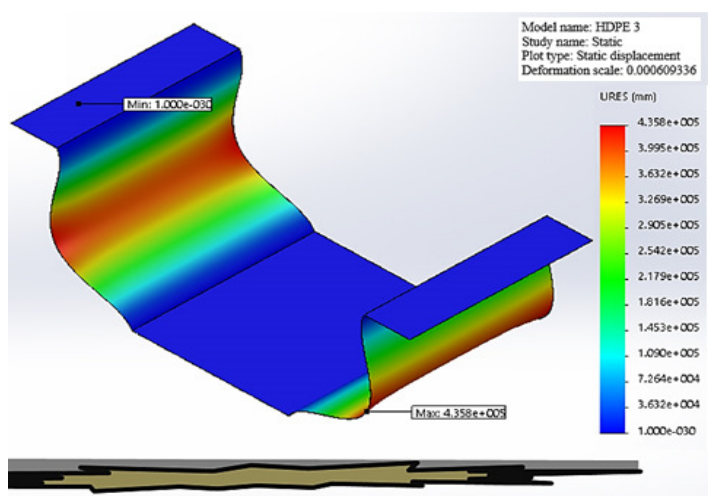

Fig. 6. Displacement on HDPE Liner with improper Contact with the Landfill internal Surfaces

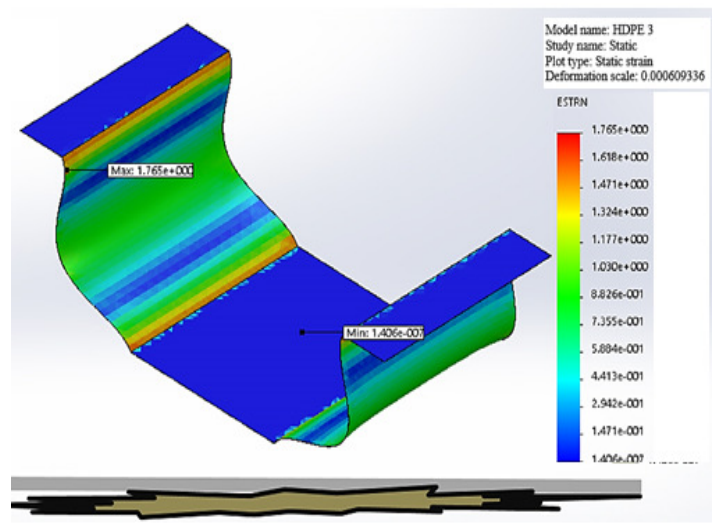

Fig. 7. Equivalent Strain on HDPE Liner with Improper Contact with the Landfill Internal Surfaces

The maximum von-mises stress distribution obtained for the HDPE lining material that was in proper contact with the side walls and base of the landfill system was $0.0180866 \mathrm{MPa}$ with maximum displacement of $8.40691 \mathrm{e}-005 \mathrm{~mm}$ and maximum equivalent strain of $1.13298 \mathrm{e}-005$ as shown in the Solidworks simulation in Fig 8-10.

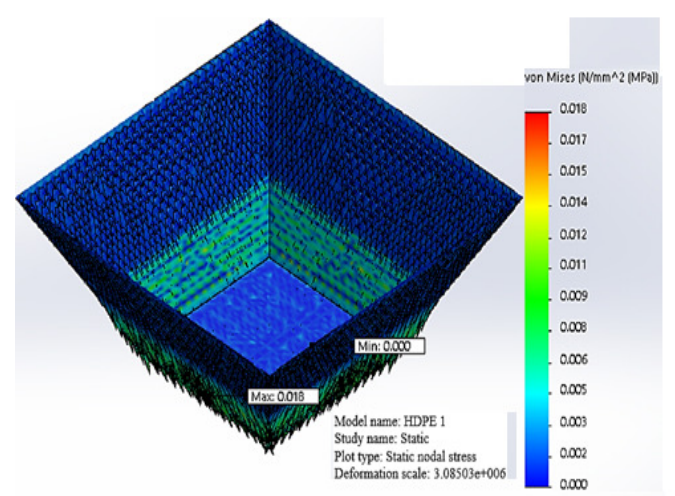

Fig. 8. Stress Distribution on HDPE Liner with Proper Contact with the Landfill Internal Surfaces

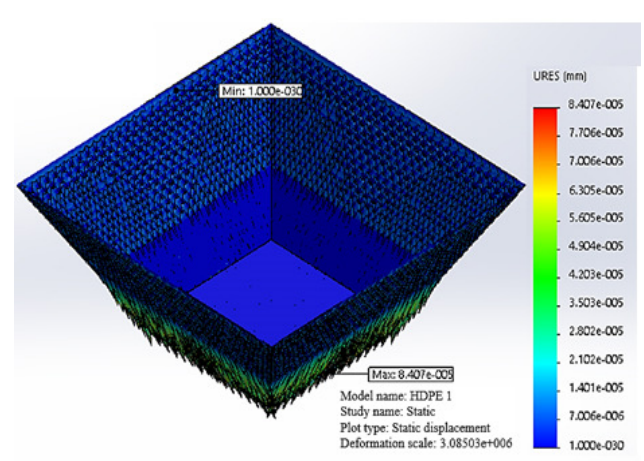

Fig. 9. Displacement on HDPE Liner with Proper Contact with the Landfill internal Surfaces

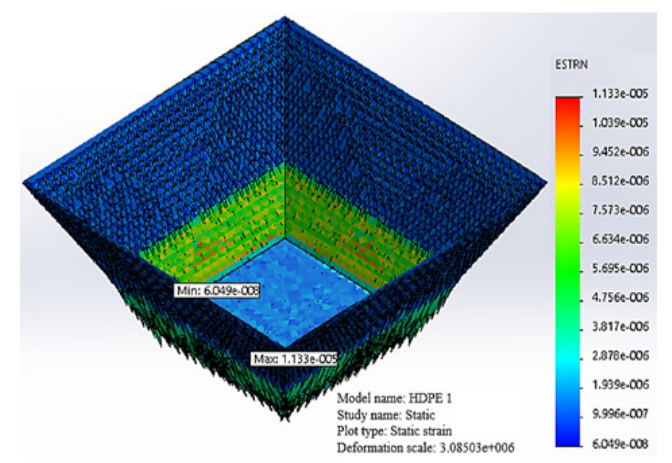

Fig. 10. Equivalent Strain on HDPE Liner with proper Contact with the Landfill Internal Surfaces

Considering the Von-mises failure theory discussed earlier, maximum Von-mises stress obtained from the static analysis when the HDPE liner is properly aligned with the base and side walls of the landfill system (when proper contact is established) is $0.018 \mathrm{~N} / \mathrm{mm}^{\wedge} 2$ which corresponds with the stress in scenario 7 of Solidworks design study for optimal performance presented in Table 2. In this case, the simulated maximum Von-mises stress obtained when proper contact is established between the liner, base and sidewalls of the landfill system is lower than 
$29.5 \mathrm{~N} / \mathrm{mm}^{\wedge} 2$ yield strength of the HDPE liner. This implies that the liner still has the capacity to withstand the external load uniformly acting on it. Moreover, since there is proper contact between the liner, base and sidewalls of the landfill system, very limited space/room exists for the liner to undergo stretching, as such, the material is barely exposed to strain and the atomic bonding within its molecular structure would barely displace. This is as a result of the solid-base and sidewalls of the landfill system which provides inertia that is equivalent to or tends to overcome the external load (force) acting on the liner. Thus, the lining material subjected to such condition continues to exhibit maximum Von-mises stress that is apparently lower than its yield strength as well as relatively low equivalent strain and resultant displacement as shown in Figure 8-10. Hence, the results obtained in Fig 5-7 is an indication that the lining material may not reach its design life if any part of the material during installation on the landfill system is in tension under the influence of applied load. As shown in Fig 8-10, the results indicated that establishing proper contact between the HDPE liner and the internal surfaces of the landfill system is an important factor that must be considered during the installation phase of the liner for longevity and optimum performance of the material in its service life.

Conclusion: Static analysis carried out on the landfill primary liner revealed that unless the High Density Polyethylene lining material aligns properly with the base and side walls of a landfill system, the lining material may be prone to high stresses, strain elongation, imperfections as well as low tear resistance which may result in unforeseen failure of the lining material in service condition. This must be accounted for, during the installation process of geomembrane liner in a landfill system.

\section{REFERENCES}

Ikpe, AE; Owunna, IB; Agho, N (2019a). Physiochemical Analysis of Municipal Solid Waste Leachate from Open Dumpsites in Benin City Metropolis. J. Appl. Sci. Environ. Manage. 23(1): 165-171

Ikpe, AE; Ebunilo, PO; Sadjere, EG (2019b). Effects of waste dumpsites on geotechnical properties of the underlying soils in wet season. Environ. Eng. Res. 24(2): 289-297.

Ikpe, AE; Ebunilo, PO; Okovido, J (2018). Geotechnical Evaluation of Bentonite Clay for Municipal Solid Waste Landfill Lining Membrane. Appl. J. Environ. Eng. Sci. 4(3): 337351.
Rowe, RK; Yu, Y (2013). A Practical Techniques for Estimating Service Life of MSW Leachate Collection System. Can. Geotech. J. 50: 165-178.

Rowe, RK (2001). Liner Systems, Geotechnical and Geoenvironmental Engineering Handbook, Chapter 25. Kluwer Academic, Norwell, USA, 25: 739-788

Rowe, RK; Abdelaal, FB; Brachman, RW (2013). Antioxidant Depletion of HDPE Membrane with Sand Protection Layer, Geosyn. Int. 20(2): 73-89.

Rowe, RK; Sangam, HP (2002). Durability of HDPE geomembranes. Geotex. Geomem. 20: 77-95.

Orhorhoro, EK; Ikpe, AE; Ukwaba, SI (2018). Effects of Landfill Gas Flow Trajectories at Three Distinct Temperature Phases on the StressStrain-Displacement Properties of a Gas Extraction Pipe. J. Appl. Sci. Environ. Manage. 22(11): 1737-1743.

Apse, JL (1989). Polyethylene resins for geomembrane applications. In: Koerner, R.M. (Ed.), Durability and Aging of Geosynthetics. Elsevier Applied Science Publisher, Amsterdam, Netherlands, 159-176.

Jafari, NH; Stark, TD; Rowe, RK (2014). Service Life and Design Implication of HDPE Geomembranes at Elevated Temperature Landfills. J. Hazard. Toxic. Radioact. Waste. 18(1): 16-26.

Kocasoy, G; Curi, K (1995). The UmraniyeHekimbashi Open Dump Accident. J. of Waste Manage. Res. 13: 305-314.

Ikpe, AE; Owunna, IB; Satope, P (2017). Design optimization of a B-pillar for crashworthiness of vehicle side impact. J. Mech. Eng. Sci. 11(2): 2693-2710.

Loo, L; Sin, LT; Bee, S; Ratnam, CT; Tee, T; Rahmat, AR (2018). Mechanical Behaviour of the Polyethylene-Devulcanized Natural Rubber Compound upon Natural Weathering. J. Phys. Conf. Ser. 1083: 1-8.

Blight, G (2008). Slope Failures in Municipal Solid Waste Dumps and Landfills: A Review. J. Waste Manage. Res. 26: 448-463. 
Alberto, P (2011). Landfill Liner Failure: An Open Question for Landfill Risk Analysis. J. Environ. Protech. 2: 287-297.

Owunna, I; and Ikpe, AE (2019). Modelling and Prediction of the Mechanical Properties of TIG Welded Joint for AISI 4130 Low Carbon Steel Plates Using Artificial Neural Network (ANN) Approach. Nig. J. of Technol. 38(1): 117 - 126.

Das, MB; Khaled, S (2017). Principles of Geotechnical Engineering, 9th Edition. Course Technology, ISBN13: 9781305970939.

Qian, X; Koerner, RM; Gray, DH (2001). Geotechnical Aspects of Landfill Design and Construction. Pearson Education (US), ISBN13: 9780130125064.

Koerner, RM (2012). Design with Geosynthetics, $6^{\text {th }}$ Edition Vol. 1. Xlibris Cooperation, Bloomington IN, USA, ISBN13: 9781462882892.
Shakeri, H; Shoeybi, M; Salvacion, JL (2012). Experimental Analytical Simulation Method in Landfill Geomembrane Liner Design. Int. J. Environ. Sci. Dev. 3(2): 161-166.

Ikpe, AE; Owunna, I (2017). Design of Vehicle Compression Springs for Optimum Performance in their Service Condition. Int. J. Eng. Res. Afr. 33: 22-34.

Xue, Q; Zhang, Q; Li, Z; Xiao, K (2013). The Tension and Puncture Properties of HDPE Geomembrane under the Corrosion of Leachate. Mater, 6: 41104121.

EPA Environmental Protection Agency (2014). Siting, design, operation and rehabilitation of landfills. Best Practice Environmental Management. EPA, 778 Victoria, 200 Victoria Street, Carlton.

Thusyanthan, NI; Madabhushi, SP; Singh, S (2007). Tension in Geomembranes on Landfill Slopes under Static and Earthquake Loading-Centrifuge Study. Geotex. Geomem. 25: 78-95. 